\title{
Aza-Morita-Baylis-Hillman Synthesis of Benzoxazepines
}

Gategory

Synthesis of

Heterocycles

Key words

benzoxazepines

aza-Morita-BaylisHillman reaction

triphenylphosphine<smiles>Cc1ccc(S(=O)(=O)/N=C/c2ccncc2O)cc1</smiles><smiles>CC=C=CC(=O)O</smiles>

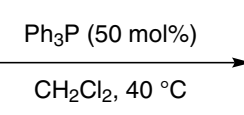

$\mathrm{R}^{1}=5-\mathrm{Br}, 5-\mathrm{Cl}, 3-\mathrm{Cl}, \mathrm{H}, 5-\mathrm{Me}, 5-\mathrm{t}-\mathrm{Bu}, 5-\mathrm{OMe}$ $\mathrm{R}^{2}=\mathrm{Me}, \mathrm{Et}, \mathrm{Bn}$

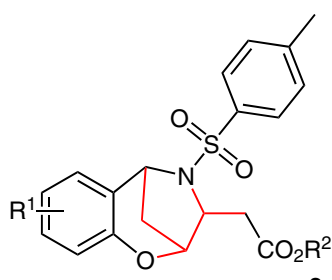

$0-71 \%$ yield
Significance: The benzoxazepine skeleton is present in compounds with important anticonvulsant, antipsychotic, and cytotoxic properties. Methods for the preparation of benzoxazepines involve either $\mathrm{C}-\mathrm{C}$ or $\mathrm{C}-\mathrm{N}$ ring closure, some of them using transition-metal catalysis (M. Rueping, A. Kuenkel, R. Fröhlich Chem. Eur. J. 2010, 16, 4173). Since removal of residual metallic impurities from pharmaceutical products is difficult and increases the final cost, it is important to develop metal-free reactions. Reported is a triphenylphosphine-catalyzed reaction of salicyl $N$-tosylimines with allene esters to synthesize benzoxazepine derivatives. The allenoates were easily obtained by Wittig reaction of the propanoyl chloride and alkoxy or benzyloxy carbonylmethylene-triphenylphosphorane, to avoid the use of expensive commercially available allenes.
Comment: The reported reaction was weakly explored in terms of scope of substituted salicyl $\mathrm{N}$-tosylimines. The electron-donating methyl and tert-butyl groups clearly decreased the reaction yields and methoxy groups prevented the reaction from occurring. When $\mathrm{R}^{2}$ was changed to a $t$-Bu group, compound $\mathbf{4}$ was obtained in 69\% yield instead of the expected benzoxazepine. Interestingly, this structural skeleton is also the final intermediate in the proposed mechanism, prior to a Michael addition of the $N$-tosyl-protected nitrogen on the double bond. Whether this means that the proposed mechanism is correct or not, is unclear, as more mechanistic evidence was not offered. 